\title{
Gift Exchange within a Firm : Evidence from a Field Experiment
}

\author{
Charles Bellemare* $\quad$ Bruce Shearer $^{\dagger}$
}

June 19, 2007

\begin{abstract}
We present results from a field experiment testing the gift-exchange hypothesis inside a tree-planting firm paying its workforce incentive contracts. Firm managers told a crew of tree planters they would receive a pay raise for one day as a result of a surplus not attributable to past planting productivity. We compare planter productivity - the number of trees planted per day - on the day the gift was handed out with productivity on previous and subsequent days of planting on the same block, and thus under similar planting conditions. We find direct evidence that the gift had a significant and positive effect on daily planter productivity, controlling for planter-fixed effects, weather conditions and other random daily shocks. Moreover, reciprocity is the strongest when the relationship between planters and the firm is longterm.
\end{abstract}

JEL Codes: J33, M52, C93

Keywords: Reciprocity, gift exchange, incentive contracts, field experiments.

\section{Introduction}

The modern economic theory of the firm emphasizes the role of labour as a unique factor of production. The recognition that workers can control their own productivity has led economic theorists to a detailed study of incentives, contracts

\footnotetext{
*Département d'économique, Université Laval, CIRPÉE, \{email: Charles.Bellemare@ecn.ulaval.ca\} .

†Département d'économique, Université Laval, CIRPÉE, \{email: Bruce.Shearer@ecn.ulaval.ca\} . We thank Sabine Kröger, Simon Gächter, Armin Falk, and John List for helpful comments. We also thank seminar participants at the Universite Laval and participants at the February 2007 conference entitled "Reciprocity: Theories and Facts" held in Verbania, Italy. We acknowledge research support from SSHRC and the Canada Research Chair in Social Policies and Human Resources at the Université Laval.
} 
and the internal worker-firm relationship; see, for example, Hart and Holmstrom (1987), Milgrom and Roberts (1992), Lazear (1998). One branch of this literature has concentrated on models of social interaction and gift exchange. The origins of these models can be traced to sociology and anthropology; see Mauss (1990) for a historical overview. Their theoretical foundations are based on the principle of reciprocity, stating that gifts received bring with them the obligation of returning gifts. ${ }^{1}$ Economic interest in gift exchange derives from the possibility of its use as an effort-eliciting device within firms (Akerlof, 1982). What is more, models of gift exchange have been shown to give rise to wage rigidity and involuntary unemployment (Akerlof, 1984), generating macroeconomic as well as microeconomic implications; see Fehr and Gächter (1998) for a review.

If gift exchange is an important factor in labour markets, then some version of the principal of reciprocity must be at work within the firm. Much of the empirical work designed to evaluate the economic relevance of these models has, therefore, concentrated on detecting the economic relevance of reciprocity.

Identifying reciprocity is problematic using observational data. Many of the forcing variables that determine the response to the gift, such as effort costs and alternative wages, are unobservable. This has led many researchers to use laboratory experiments to evaluate these effects. The laboratory permits extensive control over the economic environment, allowing researchers to generate exogenous gifts and to observe participants' reaction to them. Many laboratory studies suggest that gifts in the form of increased wages are reciprocated by workers in the form of increased productivity; see, for example, Fehr, Kirchsteiger et Reidl (1993), Fehr and Gächter (2000), Hannan, Kagel and Moser (2002) and Charness (2004). These results have been interpreted as supporting the principal of reciprocity as an economic phenomenon. This suggests that gift exchange can be an effective

\footnotetext{
${ }^{1}$ An alternative interpretation is given by Carmichael and MacLeod (1997): gifts exchanged at the beginning of a long-term relationship may serve to support cooperation.
} 
mechanism for improving performance within firms.

One concern with laboratory experiments is generalizability. The laboratory may represent an artificial environment which affects participants' behaviour. An early example is the experiments conducted at the Hawthorne Works of the Western Electric Company (Gillespie, 1991). French (1953) suggested that field experiments would improve generalizability by allowing the observation of participants within a natural setting. Field experiments have proved useful in measuring the incentive effects of different contracts; see, for example Shearer (2004) and Bandiera, Barankay, and Rasul (2007)). However, recent field experiments on gift giving have led to mixed results on the importance of reciprocity within the real economy. While Falk (2007) found that gift-giving significantly raised charitable donations, other work suggests it has insignificant effects within the labour market. In particular, Gneezy and List (2006) tested for the importance of gift giving in shortterm, spot-market-like, transactions within the labour market. Individuals who were hired for one day to perform a task under a fixed-wage payment reciprocated to gifts only during part of the work day. Kube, Maréchal and Puppe (2006) replicated part of the Gneezy and List (2006) study and found that the gift had no significant effect on productivity at any point during the work day. These results raise doubts as to the importance of gift exchange within the labour market.

However, most labour-market transactions occur within firms. Firms often differ from spot markets by the presence of long-term employment relationships (Simon, 1991) which may affect reciprocity and gift exchange (Falk, Gächter and Kovács, 1999, Gächter and Falk, 2002). Consequently, an important extension to our understanding of the economic importance of reciprocity in the "real world" will be obtained by considering its significance within actual firms. This paper presents a step in this direction - we exploit data from a field experiment, conducted within an economic firm, to measure the reaction of workers to a monetary gift from their employer. We also test whether the measured reaction to the gift is 
affected by the length of the relationship between the firm and its workers.

Our experiment was conducted within a tree-planting firm operating in British Columbia, Canada. Workers in this firm are typically paid piece rates, their daily earnings are strictly proportional to the number of trees they plant. Moreover, these workers do not have to perform any other task apart from tree planting. Hence, the number of trees planted accurately summarizes worker daily productivity. $^{2}$

Workers in this firm exhibit differing lengths of employment relationships; tenure (years completed in the firm) varies between 0 and 14 years. These workers earn, on average, approximately $\$ 200$ per day. During the experiment workers received a surprise bonus of $\$ 80$, in addition to their regular piece rate, for one day's planting. Workers were told that this bonus was a one-time event, not to be repeated. To allow the measurement of reciprocal behaviour, the bonus was formulated as a gift from the firm to the workers. Workers were told that extra money was available in the contract and that the firm had decided to distribute that money among the workers. As a result, workers were unaware that they were participating in an experiment. $^{3}$

The experiment was conducted on a large homogeneous block of land permitting the observation of workers, with and without the bonus, under homogeneous planting conditions. Eighteen planters took part in the experiment which took place in the early summer of 2006. The block was planted over a seven-day period and the bonus was paid on the second day of planting on the block. Each worker involved in the experiment is observed planting with and without the bonus. In

\footnotetext{
${ }^{2}$ Planted trees are subject to quality checks by the firm. These checks can result in fines to the worker if quality standards are not met. Discussions with the firm manager revealed that quality problems occur very rarely - none were reported in our data.

${ }^{3}$ Discussions with the firm manager revealed that he had never given such a bonus in the past. We are therefore confident that gift giving does not play a significant role in the personnel policy of the firm.
} 
total, the experiment provides 84 observations on daily productivity (the number of trees planted). We use our panel data to estimate the effect of the gift on planter productivity, controlling for planter-fixed effects, weather conditions, and other random daily shocks. Our results suggest that the principle of reciprocity does influence worker behaviour within this firm. Workers responded positively to the gift by increasing their average daily production by 113 trees, approximately 10 percent.

To gain precision in the estimation of daily weather shocks, and to control for day-of-the-week effects (possibly due to fatigue), we expanded our data set to include information on the daily productivity of the experimental participants over a period of six weeks. This combined data set allows us to identify the effect of the gift by comparing average productivity on the day of the gift with average productivity both on and off the experimental block, and within and outside of the experimental week. Again, we find that the gift significantly raises average daily planter productivity, by 117 trees, an estimate comparable to that obtained using information on the experimental block alone.

Our results also suggest that reciprocity is significantly affected by tenure within the firm; individuals with high tenure react more to the gift than do individuals with low tenure. This suggests that spot-market gift-exchange experiments, in which employment relationships are necessarily short term, may calculate a lower bound to the importance of reciprocity within the firm. Moreover, we find that planters with high tenure still reciprocate significantly more than workers with low tenure several days after the gift was given. However, the magnitude of the effect is considerably smaller for all planters. We find that the effect of the gift on subsequent days of planting is not significant when averaging over all planters.

Our results are also notable for the fact that the gift has an effect on productivity even in the presence of explicit incentives. Standard principal agent models assume that worker marginal cost of effort is increasing with the level of effort. 
Because workers have an incentive to exert greater effort when paid piece-rates as opposed to fixed wages ${ }^{4}$, it should be more costly for them to reciprocate the gift offered by the firm.

The rest of the paper is organized as follows. In the next section we present institutional details of the tree-planting industry and the firm in which the experiment took place. Section 3 presents the design of the experiment. Section 4 presents the data analysis. Section 5 discusses our results and Section 6 concludes.

\section{Tree Planting in British Columbia}

\subsection{The Industry}

While timber is a renewable resource, active reforestation can increase the speed at which forests regenerate and also allows the control of species composition. In British Columbia, extensive reforestation is undertaken by both the Ministry of Forests and the major timber-harvesting firms.

Tracts of land that have recently been logged are allocated to tree-planting firms through a process of competitive bidding. These auctions typically take place in the autumn of the year preceding the planting season, which generally runs from early spring through to late summer. Tree-planting firms submit bids over the price per tree (or bid price) that they will receive to complete a given contract. These bids are calculated after having observed the planting conditions (eg. the slope and rockiness of the terrain) on the land to be planted. These conditions affect the number of trees that can be planted in a given day and therefore affect labour costs. The lowest-bidding firm wins the contract, returning to the site the following year with hired workers to plant trees.

Tree planting is a simple, yet physically exhausting, task. It involves digging

\footnotetext{
${ }^{4}$ See Paarsch and Shearer (2000), Shearer (2004) for empirical verification within the treeplanting industry.
} 
a hole with a special shovel, placing a seedling in this hole, and then covering its roots with soil, ensuring that the tree is upright and that the roots are fully covered. The amount of effort required to perform the task depends on the terrain on which the planting is done and weather conditions. Flat plateaux are much easier to plant than steep mountain sides and hard, rocky soil is more difficult to plant than soft terrain. British Columbia is a very mountainous region of Canada; the terrain can vary a great deal from site to site.

Planters are predominantly paid using piece-rate contracts, although fixed wages are used on occasion. ${ }^{5}$ Under piece-rate contracts, planters are paid in proportion to their output. Generally, no explicit base wage or production standard exists, although firms are governed by minimum-wage laws. Output is measured as the number of trees planted per day.

\subsection{The Tree-Planting Firm}

Our experiment was conducted within a medium sized tree-planting firm that employed approximately 70 planters in the 2006 planting season. The planters represent a very broad group of individuals, including returning seasonal workers and students working on their summer holidays. They range in age from 19 to 56.

This firm pays its planters piece rates, exclusively; daily earnings for a planter are determined by the product of the piece rate and the number of trees the planter planted on that day. Blocks to be planted typically contain between 20 and 30 planter-days of work, with some lasting over 100 planter-days. For each block, the firm decides on a piece rate that applies to all planting done on the block. The piece rate for a particular block is set as a function of the planting conditions on that block. ${ }^{6}$ Since planting conditions affect the number of trees that workers can

\footnotetext{
${ }^{5}$ See Paarsch and Shearer (2000) for a discussion of when firms use fixed wage contracts and the effects of these contracts on worker productivity.

${ }^{6}$ The piece rate is not adjusted to take account of daily weather conditions.
} 
plant, blocks for which average conditions are more difficult require higher piece rates to attract planters.

Contracts, comprising a number of blocks in the same geographic area, are planted by crews of workers under a supervisor. Each crew typically has from 10 to 20 planters. All workers planting on the same block receive the same piece rate; no matching of workers to planting conditions occurs. Typically, planters are assigned to plots within a block as they disembark from the ground transportation taking them to the planting site. They also have little contact with other workers during their work day. Thus, to a first approximation, planters were randomly assigned to plots.

\section{Experimental Design}

The experiment took place on one homogeneous planting block which was planted over a seven-day period in June, 2006. This seven-day period was spread over two weeks. The first and second days of planting on the block took place on Thursday and Friday of the first week. The remaining 5 days of planting on the block took place from Monday to Friday of the following week. The piece rate paid to planters on this block was $\$ 0.20$ per tree. Eighteen planters were involved in the experiment, each planting between two and seven days on the experimental block. All eighteen planters were present for the second and third days of planting on the experimental block.

Upon arrival at the experimental block for the second day of planting, planters were informed that they would receive a bonus of $\$ 80$ for that day's work, in addition to the regular piece rate of twenty cents per tree. In order to avoid any effects of the experiment on participation, the bonus was presented to the planters after they had departed from the base camp.

An important aspect of our design is that workers were unaware that they were 
participating in an experiment. This allowed us to formulate the bonus as a gift to the planters from the firm and to observe the worker's response to that gift in their natural work environment. To this end, planters were told that there was extra money in the contract since some of the previously-planted blocks had been expected to present access problems to the workers. This caused the firm to bid "walkin" compensation to the contract for those blocks. ${ }^{7}$ In the end, the access problems did not materialize and the compensation was not needed. In spite of this, the manager had decided to share the extra money with the planters. This represented a realistic explanation to the workers since access problems occur occasionally and "walkin-fees" are the typical solution of the firm when they occur. ${ }^{8}$

A second important feature of our design is that workers were told the gift was a one-time event that would not be repeated. This ruled out the workers interpreting the gift as an efficiency wage under which present-day performances are rewarded by earning a future surplus; see, Shapiro and Stiglitz (1984) or Macleod and Malcolmson (1989).

Finally, the manager was instructed to treat the day of the gift as a normal working day: planters worked the same number of hours as a regular workday and were monitored in the same way. What is more, the manager reported that nothing out of the ordinary (such as a truck breaking down or trees being delivered late) occurred on that day that would affect planting.

\section{Data}

Our primary data contain information on the number of trees planted and the payment received for each day of planting. We have supplemented these production data with information on the daily temperature to control for extraneous weather

\footnotetext{
7“Walkin-fees” compensate planters for time spent walking into planting sites and are bid into contracts to plant sites that are difficult to access.

${ }^{8}$ None of the planters questioned this explanation.
} 
shocks that may affect productivity. We have 84 planter-day observations on the experimental block. We also created a second data set, combining data from our experimental block with planting data on the same workers, on blocks planted in close geographical proximity to the experimental block during the months of May and June 2006. To construct this extended data set, we restricted ourselves to planting data for those 18 planters who were observed planting on the experimental block. This provides us with a sample of 678 planter/day observations over 53 planting days and 11 weeks.

Our empirical analysis will use both the experimental and the extended data sets. The extended data set will allow us to control for effects attributable to planting on different days of the week, which can reflect worker fatigue. This may be particularly important since the gift was given to planters on the last day of the week, a day where worker productivity could be possibly low. It will also allow us to control for daily weather effects with more precision.

Table 1 presents statistics on planting, earnings, minimal and maximal daily temperatures, and days of week on which planting occurred. We report statistics separately for the experimental block and for the extended data set (which includes the experimental block). The first column presents statistics from the experimental block. Recall, all 18 planters were observed on the second and third days of planting on this block. A varying subset of planters were observed on the other days. The gift was offered to planters on the second day. Table 1 reveals that average planter productivity is approximately 1,000 trees per day on the experimental block. Despite the fact that the soil and planting conditions were kept constant throughout the seven days, we find some variation in temperature across the planting days, with an average maximal temperature of 30.92 degrees Celsius and a standard deviation of 4.021. ${ }^{9}$ The piece rate paid to workers on this block was $\$ 0.20$ per tree planted and average earnings (net of the bonus) were equal to

\footnotetext{
${ }^{9}$ There was negligible rainfall during the experimental period.
} 
\$216, with a standard deviation of $\$ 56$.

The second column of Table 1 presents the descriptive statistics from the extended sample. The average piece-rate across all the blocks is slightly higher than on the experimental block alone ( $0.23 \$$ vs. $0.20 \$$ per tree), indicating that the nonexperimental blocks where somewhat more difficult to plant than the experimental block. This is reflected in the slightly lower average productivity per planter (987.82 trees per planter). Temperatures were considerably higher during planting on the experimental block: average maximal temperature was 31 degrees centigrade on the experimental block and 24 degrees centigrade during planting on all blocks. Notice, however, that the average daily earnings are practically identical between the experimental on non-experimental blocks $(\$ 219$ in the extended sample vs. $\$ 216$ in the experimental sample) suggesting that the piece rate is compensating workers for the differences in planting conditions.

\section{Results}

In this section we use regression analysis to estimate the effect of the gift on average planter productivity. We will use the number of trees planted on a given day by a planter as our dependent variable. This provides us with an unbalanced panel since not all 18 planters are observed planting on the experimental block each day.

To estimate the effect of the gift on productivity, we specify the following model of planter productivity

$$
\text { productivity }_{i t}=\beta_{0}+\gamma \text { Gift }_{i t}+\beta_{1} \text { Mintemp }_{t}+\beta_{2} \text { Maxtemp }_{t}+\mu_{i}+\lambda_{t}+\epsilon_{i t}
$$

where Mintemp $p_{t}$ and Maxtemp $p_{t}$ denote the minimal and maximal temperatures on day $t$ recorded in the area of planting, $\mu_{i}$ represents a fixed, individual-specific effect for planter $i, \lambda_{t}$ represents a mean-zero, random daily effect with constant variance, and $\epsilon_{i t}$ denotes a, possibly, heteroscedastic mean-zero error term varying 
across individuals and time periods. ${ }^{10}$ We estimate different versions of (1) on both the experimental block and the extended sample using the ordinary-leastsquares estimator; the results are presented in Table 2. Reported standard errors are corrected for clustering due to the presence of the random daily effect $\lambda_{t}$ and for arbitrary forms of heteroscedasticity in $\epsilon_{i t}$ (see Cameron and Trivedi (2005) for details).

The first and second columns of Table 2 present results from estimating (1) based on the experimental sample, using ordinary least squares. Column I presents results, excluding temperature controls. We find that the average productivity is higher on the gift-day (in the order of 73 trees), and the difference is marginally statistically significant; the p-value is equal to 0.077. After controlling for temperature (column II), we find that the effect of the gift is positive and statistically significant : daily productivity significantly increased by 113.42 trees on the giftday ( $p$-value $=0.002)$. Adding controls for weather appears to pick up a significant amount of variation in daily productivity on the experimental block. In particular, planter productivity significantly increases with the minimum temperature $(p$-value $=0.033)$, and significantly decreases $(p$-value $=0.001)$ with the maximum temperature, reflecting the physical nature of tree planting. These results provide significant support for the gift-exchange hypothesis. They suggest that workers in our sample have reacted positively to the gift received from the firm, reciprocating with a gift of increased productivity.

The second set of regressions measures the effect of the gift on productivity using planting data from the extended sample, combining data from the experimental block with planting data on the experimental participants, planting on non-experimental blocks in the same proximity. Adding these additional data allows us to compare productivity on the day of the gift with productivity on non-

\footnotetext{
${ }^{10}$ Daily precipitation and quadratic terms in temperature are insignificant in our specifications and are omitted.
} 
experimental blocks over several different days and weeks. It also allows us to consider day-of-the-week effects which may be caused by fatigue. It does, however, require that we control for differences in the difficulty of planting conditions across blocks. We do so by extending the model in (1) to account for differences in terrain as well as day-of-the week effects using the following model

$$
\begin{aligned}
\text { productivity }_{i j t}= & \beta_{0}+\gamma \text { Gift }_{i t}+\beta_{1} \text { Mintemp }_{t}+\beta_{1} \text { Maxtemp }_{t} \\
& +\beta_{2} \text { Tuesday }_{t}+\beta_{3} \text { Wednesday }_{t}+\beta_{4} \text { Thursday }_{t}+\beta_{5} \text { Friday }_{t} \\
& +f\left(\text { Terrain }_{j}\right)+\mu_{i}+\lambda_{t}+\epsilon_{i j t}
\end{aligned}
$$

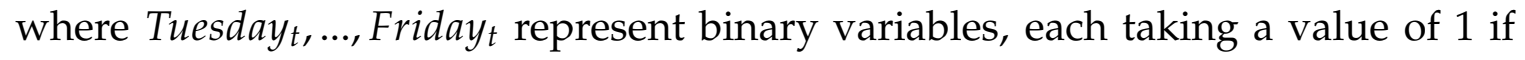
planting is done on the corresponding day, and 0 otherwise. The effect of ground conditions on block $j$ on productivity, $f\left(\right.$ Terrain $\left._{j}\right)$, is approximated using a third order polynomial in the piece-rate paid on that block. ${ }^{11}$ This approximation reflects the fact that the piece rate for a particular block is set as a function of the difficulty of the terrain on that block. Blocks for which ground conditions are more difficult require higher piece rates to attract planters. ${ }^{12}$

Results of the extended model are presented in columns III and IV of Table 2. Controlling for differences in weather and ground conditions across blocks, we find that the gift raised average productivity by 86.725 trees. This effect is significant at the $1 \%$ level. The estimated effect of the gift on average planter productivity increases to 116.987 when we also control for day-of-the-week effects. This effect is also significant at the $1 \%$ level. The linear, quadratic, and cubic terms of the polynomial in the piece-rate are individually insignificant due to the strong collinearity between these variables. An F-test of the joint significance of these variables easily

\footnotetext{
${ }^{11}$ We refrain from using block-specific dummy variables to avoid collinearity problems in (2); Planting blocks vary considerably in size, many (17 percent) include three planter days or less.

${ }^{12}$ See the discussion in section 2.2 .
} 
rejects the null hypothesis that differences in terrain across blocks does not affect planter productivity $(p$-value $=0.000)$.

The estimated standard errors reported in Table 2 are robust to daily random effects and arbitrary forms of heteroscedasticity. They do not, however, account for possible serial correlation. Serial correlation will arise if either $\lambda_{t}$ or $\epsilon_{i t}$ are correlated through time. If such were the case, regression residuals should vary systematically across time for all planters. Figure 2 presents plots of the regression residuals versus time, separately for each of the 18 planters. The residuals are based on the estimates presented in the last column of Table 2. ${ }^{13}$ Inspection of these graphs suggests that very little evidence of serial correlation exists for the 18 planters. To be more precise, we additionally estimated a planter specific correlation coefficient $\rho_{i}$ by regressing residuals on their lagged value. ${ }^{14}$ In all but one case we were unable to reject the null hypothesis that $\rho_{i}$ is equal to zero. In light of these results, we are confident that we can ignore any possible serial correlation in the disturbances of our model.

\subsection{Tenure and Reciprocity}

The previous results suggest the presence of significant reciprocal behaviour. A distinctive feature of economic firms is the presence of ongoing relationships with its workers. Recent experimental evidence suggests that the importance of reciprocity may differ between long-term and short-term relationships Gächter and Falk (2001). The 18 planters who participated in our experiment have different past histories with the firm : 8 of them are in their first year of planting with the firm, 3 are in their second year, 1 is in his fourth year, 3 are in their sixth year, and 3 are in their 15th year. In this section, we analyze how reciprocal behaviour

\footnotetext{
${ }^{13}$ Similar graphs are obtained for the other regressions.

${ }^{14}$ More precisely, we specified $\widehat{r}_{i t}=\rho_{i} \widehat{r}_{i t-1}+v_{i t}$ for all $i$, where $\widehat{r}_{i t}$ denotes the residuals, and $v_{i t}$ is a white noise disturbance. Estimation of $\rho_{i}$ was performed using the OLS estimator for all $i$.
} 
relates to worker tenure within the firm. ${ }^{15}$ To do so, we extend (1) and (2) to allow for interaction terms between age, tenure and the Gift $t_{i t}$ variable. We specify a very general function, interacting the Gift $t_{i t}$ variable with a flexible quadratic function of age and the number of completed years of tenure, as well as an interaction between age and tenure. The presence of linear and quadratic interaction terms allows for possible non-linearities in the effect of tenure and age on reciprocal behaviour. The regression results are presented in Table 3. Column I presents results on the experimental block alone and column II presents results from the extended sample. To simplify the presentation, Table 3 omits the estimated effect of the piece-rate as well as the days of the week in column II. ${ }^{16}$.

The overall statistical significance of effect of tenure on reciprocity can be evaluated by testing the hypothesis that the coefficients on the linear, quadratic and interaction terms are equal to zero. The p-value for this test is essentially zero, suggesting that tenure affects reciprocity.

In the presence of the interaction terms, the leading term in the gift variable captures the effect of the gift on planters with both age and tenure equal to zero, a parameter which has no clear economic interpretation. As might be expected, this parameter is imprecisely measured in both regressions. The quadratic term in tenure is significant and positive when using the experimental data alone, while both the linear and quadratic terms in tenure are significant and positive at the 5\% level when using the extended data set. This suggests that workers with higher tenure respond significantly more to the gift. The interaction of age with tenure is

\footnotetext{
${ }^{15}$ Note, there is one important difference between our experiment and that of Gächter and Falk. The Gächter and Falk experiment involved repeated gift-giving sessions between individuals who were matched together for different amounts of time. Since our experiment represented first occurrence of gift giving within this firm we observe the effect of long-term relationships on a one-shot gift exchange.

${ }^{16}$ The estimated effect of the piece-rate and the day of the week effects are similar to those reported in Table 2. A complete table of results is available upon request
} 
found to be negative and significant, suggesting that the effect of tenure on reciprocal behaviour diminishes with age. Figure 1 presents the predicted reciprocity profile for two of the most relevant profiles for the firm. The thick line plots the predicted response to the gift of a planter who is 20 years of age when beginning his tenure with the firm. The dashed line presents a similar predicted response for a planter who is 28 years of age when beginning his tenure with the firm. In line with our estimates, we find that the response to the gift is the highest when both workers have high tenure.

We can think of several reasons why a positive relationship may exist between tenure and reciprocity. The first explanation is learning: workers with higher tenure are more familiar with the practices of the firm and thus perceive the gift as a relatively more exceptional act, triggering stronger responses. A related explanation is that workers with higher tenure have a better understanding of the benefits to the firm of increasing their productivity (increased firm revenues, savings on daily expenditures for the planting crew, the possibility of getting additional contracts, etc...), and respond relatively more when offered a gift. ${ }^{17}$ Alternatively, repeated interaction associated with longer tenure may reduce social distance between the workers and the manager, leading to stronger reciprocal behaviour (e.g. Hoffman, McCabe, and Smith (1996), Cox and Deck (2005)). ${ }^{18}$

\footnotetext{
${ }^{17}$ Hennig-Schmidt, Rockenbach, and Sadrieh (2005) present experimental results on the gift exchange game suggesting that the positive relationship between gifts and reciprocity is no longer significant when workers do not have information about the surplus of firm.

${ }^{18}$ We note that other researchers have found similar effects in different settings. Falk, Gächter, and Kovács (1999) found that reciprocity significantly increased with the duration of the interaction between laboratory-experiment participants. Similarly, Maréchal and Thöni (2007) found that the duration of interaction between salesmen and their clients had a significant effect on reciprocity.
} 


\subsection{The Duration of Reciprocity}

It is also of interest to test whether the gift had any lasting effects on productivity. Recall, the gift was given to workers on a Friday. The first day of planting following the gift was therefore a Monday, two days hence. To test for lasting effects of the gift, we expanded the model presented in column II of Table 3 by including controls to capture the relationship between tenure and reciprocity on the Monday following the day of the gift. The results are reported in Column III of Table 3. We find that the relationship between reciprocity and tenure remains significant on the first day of planting after the gift: workers with high tenure reciprocated significantly more than workers with low tenure. However, the parameter estimates reveal that the magnitude of the estimated effect is considerably smaller than the effect measured on the day the gift was given, indicating that the response to the gift diminished for all workers. To measure the overall effect of the gift on Monday's planting we re-estimated the model of Column III removing all interactions of age and tenure with the Monday variable (results not reported). We find that the gift did not significantly affect overall average productivity on that Monday. Hence, our results indicate that planters with high tenure continued to reciprocate on the Monday after the gift, but their productivity increase was not sufficient to significantly raise the overall productivity of the entire crew.

\section{Concluding discussion}

We have presented results from a field experiment directly testing the gift-exchange hypothesis within a tree-planting firm. We have used payroll data on 18 planters who were observed working on several blocks of land for several days. Each planter received a surprise bonus from the firm on one of the planting days. We used our unbalanced panel on daily planter productivity to estimate the effect of the gift on planter productivity, controlling for planter-fixed effects, weather con- 
ditions, and other random daily shocks. Our results provide substantive support for existing theories of reciprocity : planters reciprocated to gift giving by the firm by significantly raising their productivity. Moreover, we found that the response to the gift is heterogeneous and is the strongest for planters with longer tenure within the firm. We found reciprocal behaviour dies out several days after the gift was given, but is still present (although to a lesser degree) among high-tenure planters.

These results have a number of important implications for the economic literature on gift exchange. First, and perhaps most importantly, the positive response of worker effort to a gift suggests that the principal of reciprocity does operate within actual firms. This suggests that gift exchange can be used as an effort-inducing personnel policy, at least in the short run.

Second, our field experiment allowed us to capture an empirically important link between tenure and reciprocity which cannot be uncovered by experiments conducted in spot-market-like experimental markets. We have suggested several possible explanations for a positive relationship between tenure and reciprocity. Disentangling which of these explanations is empirically relevant will require more extensive data, some of which may be difficult to collect in the field. Laboratory experiments, similar to those of Falk, Gächter and Kovács (1999), may well be the best place to start investigating these issues.

Third, several studies have observed a significant negative relationship between worker productivity and exogenous income increases. Two explanations have been put forward to explain this relationship. First, a negative relationship could simply result from a standard income effect, where workers substitute effort foron-the job leisure. Dickinson (1999) presents results from laboratory experiments corroborating such a substitution effect. Such a model cannot however predict a positive relation between productivity and base income (gifts). A decrease in productivity is also predicted by models with reference dependent preferences (see 
Tversky and Kahneman (2000)). Broadly speaking, reference dependent models argue that large exogenous increases in income make it easier for workers to exceed their subjective daily income targets, or reference points. Since there is a diminishing marginal benefit to exerting effort beyond these reference points, the exogenous increase in income lowers incentives to exert effort and hence reduces daily productivity. Fehr and Goette (2006), for example, find that a 25\% increase in the wage of bicycle messengers significantly reduces their average daily productivity. ${ }^{19}$ In our experiment, the gift offered to planters represented an increase of approximately $40 \%$ in average daily earnings, a substantial increase. Nevertheless, we observed a positive, and significant, increase in daily productivity. A crucial aspect in our study is that the increase in income was framed to workers as a gift from the firm, thereby stimulating gift exchange. This suggests that any influences of reference-dependent preferences or income effects were not strong enough to offset the reciprocal behaviour triggered by the gift.

Fourth, we found clear evidence of reciprocal behaviour within a sample of workers receiving explicit incentives to perform: they are paid piece-rates. Our results suggest that explicit incentives do not necessarily crowd out reciprocal behaviour inside real economic firms.

Finally, the worker's average reciprocal increase in productivity generated considerably less revenue than the original gift from the firm $(\$ 80)$. The output price received by the firm for trees planted was $\$ .36$ per tree - the average increase in productivity of 113 trees therefore generated only $\$ 40.68$ in revenue on the day of the gift, and no significant (average) response on the days following the gift. This raises questions as to the profitability of gift giving inside the firm. While our results might be interpreted as explaining why this firm does not normally use gifts to motivate its workforce, it may still be the case that "optimal" gifts are profitable. A definite answer would require using the (experimental) data to estimate struc-

\footnotetext{
${ }^{19}$ Also see Camerer, Babcock, Loewenstein, and Thaler (1997).
} 
tural parameters (e.g. cost of effort function) which could be used to solve for the optimal gift-incentives combination for the firm. ${ }^{20}$ We leave this task for future research.

${ }^{20}$ See Shearer (2004), Paarsch and Shearer (2007) for examples of this approach. 


\begin{tabular}{lcc}
\hline \hline & & \\
& & I \\
& & \\
& Experimental block & All blocks \\
\cline { 2 - 3 } Avg. number of trees & 1082.798 & 987.824 \\
& $(282.549)$ & $(309.824)$ \\
Avg. daily earnings & 216.559 & 219.565 \\
& $(56.509)$ & $(59.245)$ \\
Avg. minimum temperature & 12.889 & 10.731 \\
& $(1.576)$ & $(4.039)$ \\
Avg. maximum temperature & 30.952 & 24.262 \\
& $(4.021)$ & $(5.950)$ \\
Avg. piece-rate (dollar) & 0.200 & 0.228 \\
Number of Mondays & - & $(4.072)$ \\
Number of Tuesdays & 1 & 11 \\
Number of Wednesdays & 1 & 11 \\
Number of Thursdays & 1 & 11 \\
Number of Fridays & 2 & 10 \\
& 2 & 10 \\
Number of planter-day obs. & 84 & \\
& & \\
\hline \hline
\end{tabular}

Table 1: Descriptive statistics for 18 planters on the experimental block only (second column) and on all blocks planted in proximity to the experimental block. 


\begin{tabular}{|c|c|c|c|c|}
\hline & $\mathrm{I}$ & II & III & IV \\
\hline Day of gift & $\begin{array}{l}72.785^{*} \\
(34.213)\end{array}$ & $\begin{array}{c}113.415^{* * *} \\
(20.995)\end{array}$ & $\begin{array}{c}86.725^{* * *} \\
(20.705)\end{array}$ & $\begin{array}{c}116.987^{* * *} \\
41.639\end{array}$ \\
\hline Minimum temperature & & $\begin{array}{c}42.757^{* * *} \\
(13.643)\end{array}$ & $\begin{array}{l}-2.990 \\
(5.573)\end{array}$ & $\begin{array}{c}-2.227 \\
(3.891)\end{array}$ \\
\hline Maximum temperature & & $\begin{array}{c}-15.911^{* * *} \\
(2.425)\end{array}$ & $\begin{array}{l}-1.602 \\
(3.052)\end{array}$ & $\begin{array}{l}-2.067 \\
(6.849)\end{array}$ \\
\hline Piece-rate $\times 100$ & & & $\begin{array}{c}22.033 \\
(285.151)\end{array}$ & $\begin{array}{c}0.241 \\
(27.684)\end{array}$ \\
\hline Piece-rate $^{2} \times 1000$ & & & $\begin{array}{l}-0.004 \\
(0.011)\end{array}$ & $\begin{array}{l}-0.003 \\
(0.010)\end{array}$ \\
\hline Piece-rate $^{3} \times 1000$ & & & $\begin{array}{c}0.007 \\
(0.013)\end{array}$ & $\begin{array}{c}0.006 \\
(0.012)\end{array}$ \\
\hline Tuesday & & & & $\begin{array}{l}77.432^{*} \\
(40.097)\end{array}$ \\
\hline Wednesday & & & & $\begin{array}{c}42.093 \\
(71.825)\end{array}$ \\
\hline Thursday & & & & $\begin{array}{c}38.057 \\
(35.212)\end{array}$ \\
\hline Friday & & & & $\begin{array}{c}6.451 \\
(47.936)\end{array}$ \\
\hline Experimental data only & Yes & Yes & No & No \\
\hline
\end{tabular}

Table 2: Parameter estimates of the productivity equation. The first two regression columns present estimates on the experimental block only using the 84 planter-day observations. The remaining regression columns combine data both on and off the experimental block for the 18 planters who participated in the experiment. all standard errors (in parentheses) are robust to daily random effects and arbitrary forms of heteroscedasticity. ${ }^{\prime * \prime}{ }^{* * * \prime},{ }^{* * * * \prime}$ denote significance at the $10 \%$, $5 \%$, and $1 \%$ level respectively. 


\begin{tabular}{|c|c|c|c|}
\hline & $\mathrm{I}$ & II & III \\
\hline Day of gift & $\begin{array}{c}143.899 \\
(226.249)\end{array}$ & $\begin{array}{l}252.056^{*} \\
(130.312)\end{array}$ & $\begin{array}{l}260.367^{*} \\
(135.083)\end{array}$ \\
\hline Day of gift $\times$ Age & $\begin{array}{c}13.386 \\
(11.502)\end{array}$ & $\begin{array}{c}-13.427^{* *} \\
(6.669)\end{array}$ & $\begin{array}{c}-14.267^{* *} \\
(6.911)\end{array}$ \\
\hline Day of gift $\times \mathrm{Age}^{2}$ & $\begin{array}{c}-0.158 \\
(0.143)\end{array}$ & $\begin{array}{c}0.264^{* * *} \\
(0.092)\end{array}$ & $\begin{array}{c}0.281^{* * *} \\
(0.094)\end{array}$ \\
\hline Day of gift $\times$ Tenure & $\begin{array}{c}5.598 \\
(7.522)\end{array}$ & $\begin{array}{c}33.196^{* * *} \\
(8.238)\end{array}$ & $\begin{array}{c}33.918^{* * *} \\
(8.512)\end{array}$ \\
\hline Day of gift $\times$ Tenure $^{2}$ & $\begin{array}{c}5.360^{* * *} \\
(0.481)\end{array}$ & $\begin{array}{c}7.158^{* * *} \\
(0.446)\end{array}$ & $\begin{array}{c}7.251^{* * *} \\
(0.451)\end{array}$ \\
\hline Day of gift $\times$ Age $\times$ Tenure & $\begin{array}{c}-1.649^{* * *} \\
(0.326)\end{array}$ & $\begin{array}{c}-1.997^{* * *} \\
(0.172)\end{array}$ & $\begin{array}{c}-2.053^{* * *} \\
(0.170)\end{array}$ \\
\hline Monday after gift & & & $\begin{array}{c}187.484 \\
(141.556)\end{array}$ \\
\hline Monday after gift $\times$ Age & & & $\begin{array}{c}-19.601^{* *} \\
(6.912)\end{array}$ \\
\hline Monday after gift $\times \mathrm{Age}^{2}$ & & & $\begin{array}{c}0.407^{* * *} \\
(0.094)\end{array}$ \\
\hline Monday after gift $\times$ Tenure & & & $\begin{array}{c}24.618^{* * *} \\
(8.512)\end{array}$ \\
\hline Monday after gift $\times$ Tenure $^{2}$ & & & $\begin{array}{l}3.436^{* *} \\
(0.452)\end{array}$ \\
\hline Monday after gift $\times$ Age $\times$ Tenure & & & $\begin{array}{c}-1.996^{* * *} \\
(0.170)\end{array}$ \\
\hline Experimental data only & Yes & No & No \\
\hline
\end{tabular}

Table 3: Productivity equation with interactions between the gift variable with and and tenure. The first regression column present estimates on the experimental block only using the 84 planterday observations. Columns II and III combine data both on and off the experimental block for the 18 planters who participated in the experiment. Regressions in columns II and III additionally contained controls $\beta_{2}$ Tuesday $_{t}+\beta_{3}$ Wednesday $_{t}+\beta_{4}$ Thursday $_{t}+\beta_{5}$ Friday $_{t}+f\left(\right.$ Terrain $\left._{j}\right)$ whose effects are not reported in the table. All standard errors (in parentheses) are robust to daily random effects and arbitrary forms of heteroscedasticity. ${ }^{\prime * \prime},{ }^{\prime * * \prime},{ }^{\prime * * * \prime}$ denote significance at the $10 \%, 5 \%$, and $1 \%$ level respectively. 


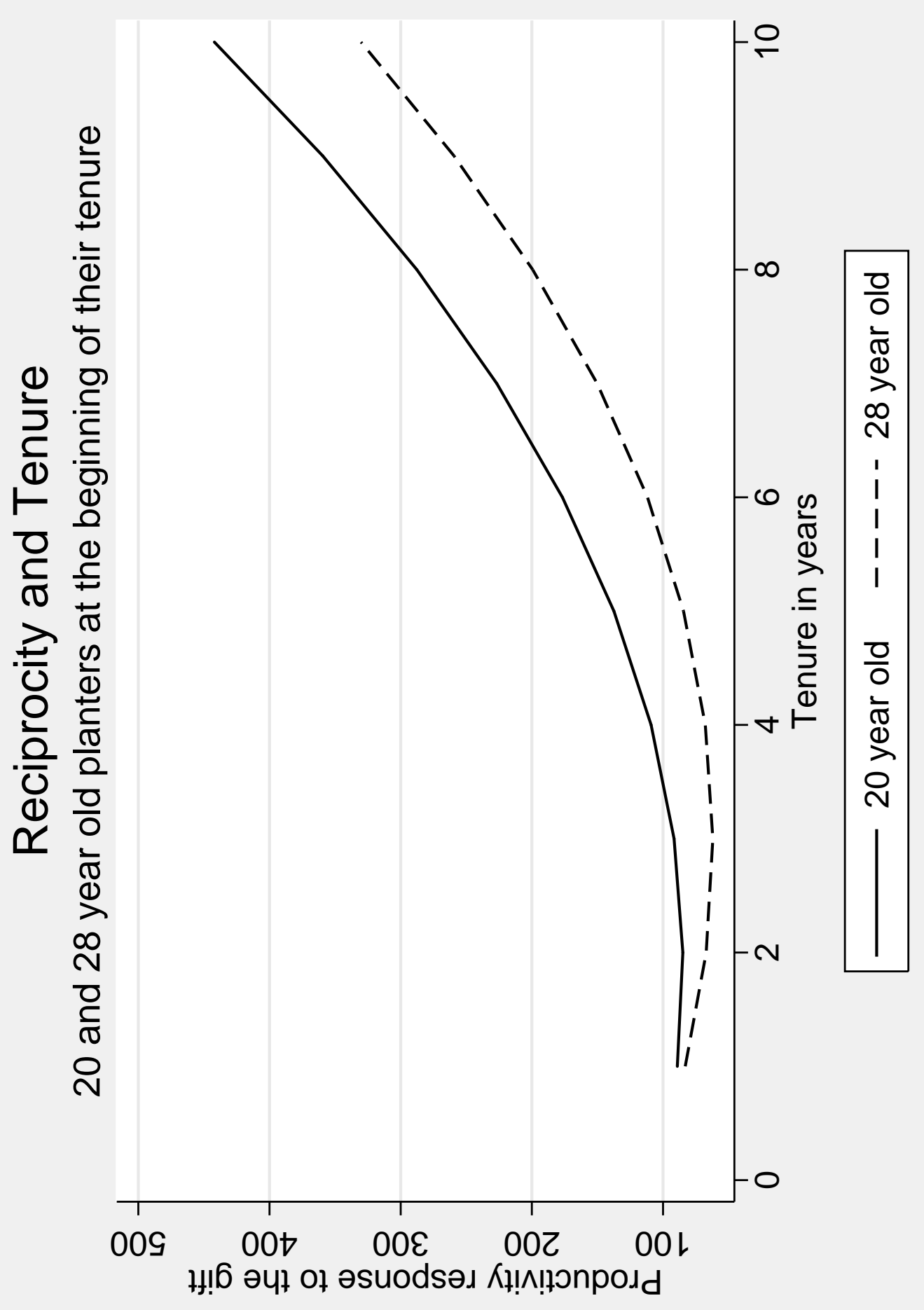

Figure 1: Simulated response to the gift for two planters: a planter with 20 years of age at the beginning of his tenure (full line) and a planter with 28 years of age at the beginning of his tenure (dashed line). 

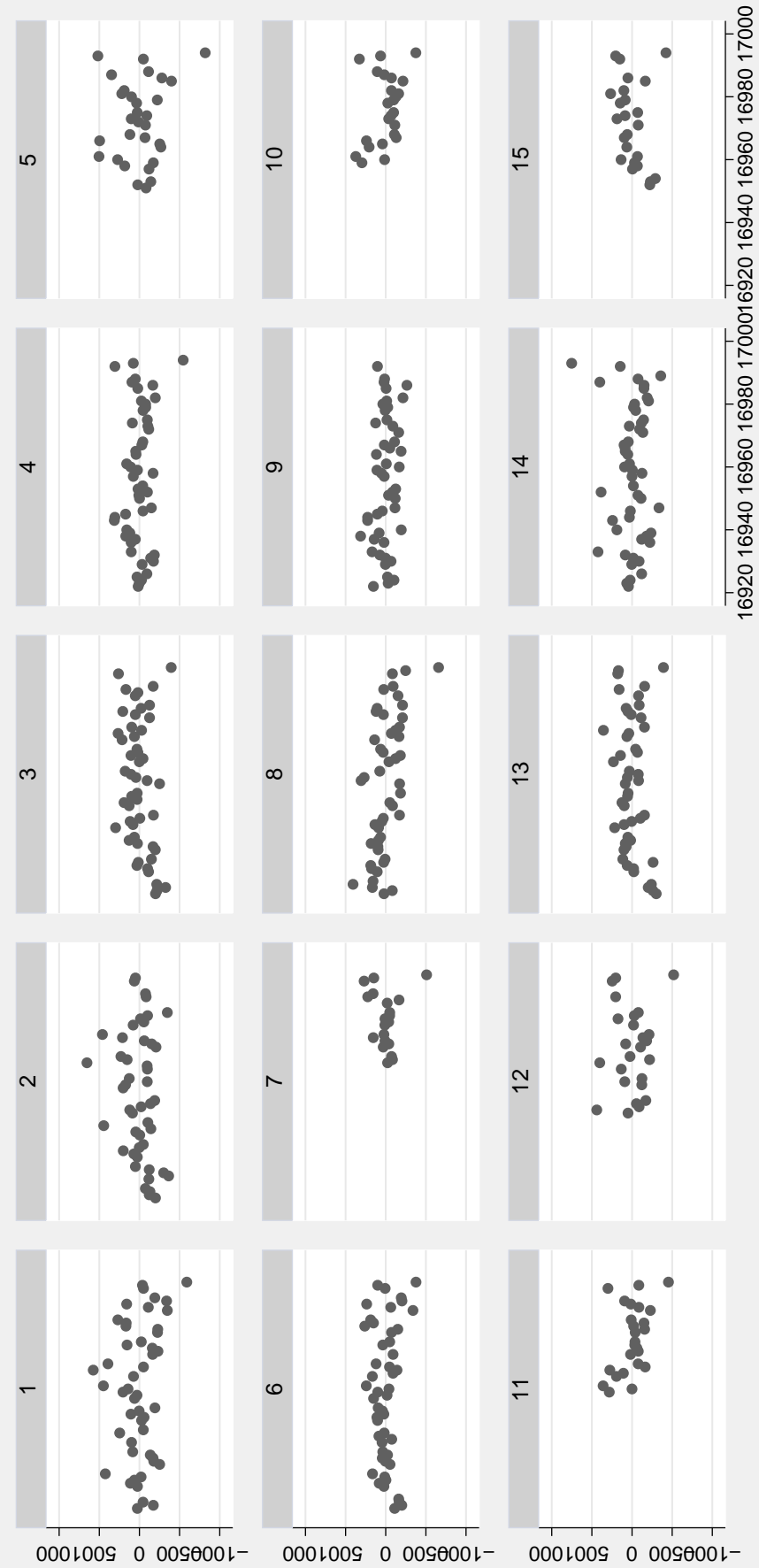

000L009 0 009000L

000L009 0 009000L-

sjenpisəy

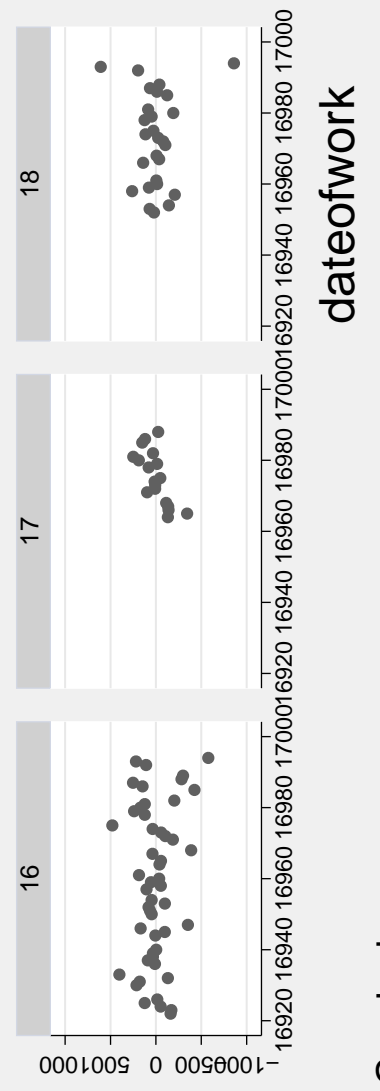

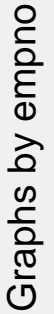

Figure 2: Regression residuals for all 18 planters who participated in the experiment. Each graph plots the residuals for a given planter against the time period. 


\section{References}

A. FALK, S. G. A., AND J. KOVÁCKS (1999): "Intrinsic motivation and extrinsic incentives in a repeated game with incomplete contracts," Journal of Economic Psychology.

ACHTER, S. G., AND A. FALK (2002): “Reputation and Reciprocity: Consequences for the Labour Relation," Scandinavian Journal of Economics.

Akerlof, G. (1982): “Labor Contracts as Partial Gift Exchange,” Quarterly journal of Economics, 97, 543-569.

(1984): “Gift Exchange and Efficiency Wage Theory: Four Views," American Economic Review, 74, 79-83.

BANDIERA, O., I. BARANKAY, AND I. RASUl (2007): “Incentives for Managers and Inequality among Workers: Evidence from a Firm Level Experiment," forthcoming, Quarterly Journal of Economics, 122.

Camerer, C., L. BAbcock, G. Loewenstein, And R. Thaler (1997): “Labor Supply of New York City Cabdrivers: One Day at a Time," Quarterly journal of Economics, 112, 407-441.

Cameron, A. C., And P. K. Trivedi (2005): Microeconometrics. Cambridge University Press, New-York.

CARMichael, L., And L. MacLeOD (1997): "Gift giving and the Evolution of Cooperation," International Economic Review, 38, 485-509.

CHARness, G. (2004): "Attribution and Reciprocity in an Experimental Labor Market," Journal of Labor Economics, 22, 665-688.

Cox, J., AND C. DECK (2005): “On the Nature of Reciprocal Motives," Economic Inquiry, 43(3), 623-635.

DiCKINSON, D. (1999): “An Experimental Examination of Labor Supply and Work Intensities," Journal of Labor Economics, 17, 638-670.

FALK, A. (2007): “Gift Exchange in the Field," forthcoming, Econometrica. 
FEHR, E., AND S. GÄCHTER (1998): "Reciprocity and Economics: The Economic Implications of Homo Reciprocans," European Economic Review, 42, 845-859.

(2000): “Cooperation and Punishment in Public Goods Experiments," American Economic Review, 90, 980-994.

FEHR, E., AND L. GOETTE (2006): "Do workers Work More when Wages are High ? Evidence from a Randomized Field Experiment," Forthcoming, American Economic Review.

Fehr, E., G. Kirchsteiger, And A. Riedl (1993): “Gift Exchange and Reciprocity in competitive Experimental Markets," Quarterly journal of Economics, 153, 437-460.

FRENCH, J. (1953): Experiments in Field Settings. in Research Methods in the Behavioral Sciences.

Gillespie, R. (1991): Manufacturing Knowledge: A History of the Hawthorne Experiments. Cambridge University Press, New York, U.S.A.

GNeEZY, U., AND J. List (2006): “Putting Behavioral Economics to Work: field Evidence of Gift Exchange," Forthcoming, Econometrica.

HANnAN, L., J. KAGEL, AND D. Moser (2002): "Partial gift Exchange in an Experimental Labor Market: Impact of Subject Population Differences Productivity Differences, and Effort Requests on Behavior," Journal of Labor Economics, 20, 923-951.

Hart, O., And B. Holmstrom (1987): The Theory of Contracts. in Advances in Economic Theory, Cambridge University Press.

HenNig-Schmidt, H., B. ROCKENBACH, AND K. SAdRIEH (2005): "In Search of Workers' Real Effort : A Field and a Laboratory Experiment," University of Magdeburg Working Paper.

Hoffman, E., K. MCCABE, And V. SMith (1996): "Social distance and OtherRegarding Behavior in Dictator Games," American Economic Review, 86(3), 653660. 
Kube, S., M. MaréChal, and C. Puppe (2006): "Putting Reciprocity to Work: Positive versus Negative Responses in the Field," University of St.Gallen Discussion Paper 2006-27.

LazeAr, E. (1998): Personnel Economic for Managers. John Wiley and Sons., New York.

MARÉCHAL, M., AND C. THÖNI (2007): “Do Managers Reciprocate ? Field Experimental Evidence From a Competitive Market," Mimeo, University of St.Gallen.

MAuss, M. (1990): The Gift. W. W. Norton, New York, U.S.A.

Milgrom, P., AND J. Roberts (1992): Economics, Organization and Management. Prentice Hall, Upper Saddle River, U.S.A.

PaArsch, H., ANd B. Shearer (2000): "Piece Rates, Fixed Wages and Incentive Effects: Evidence from Payroll Data," International Economic Review, 41, 59-92.

- (2007): "The Response to Incentives and Contractual Efficiency: Evidence from a Field Experiment," Cahier de Recherche CIRPÉE, 07.

SHEARER, B. (2004): "Piece Rates, Fixed Wages and Incentive Effects: Evidence from a Field Experiment," Review of Economic Studies, 71.

Simon, H. (1991): "Organizations and Markets," The Journal of Economic Perspectives, 5, 25-44.

Tversky, A., And D. Kahneman (2000): Choices, Values, and Frames. Cambridge University Press, Cambridge, U.S.A. 